Published in final edited form as:

PM R. 2013 January ; 5(1): . doi:10.1016/j.pmrj.2012.06.012.

\title{
Neuropsychiatric Symptoms and the Use of Complementary and Alternative Medicine
}

\author{
Maulik P. Purohit, MD, MPH, \\ Spaulding Rehabilitation Hospital, Harvard Medical School, 125 Nashua St, \#720, Boston, MA \\ 02114; Massachusetts General Hospital, Harvard Medical School, Boston, MA; and Beth Israel \\ Deaconess Medical Center, Harvard Medical School, Boston, MA
}

Rebecca Erwin Wells, MD, MPH,

Brigham and Women's Hospital, Harvard Medical School and Faulkner Hospital, Harvard Medical School, Boston, MA

Ross D. Zafonte, DO,

Spaulding Rehabilitation Hospital and Massachusetts General Hospital, Harvard Medical School, Boston, MA

Roger B. Davis, ScD, and

Beth Israel Deaconess Medical Center, Harvard Medical School, Boston, MA

Russell S. Phillips, MD

Beth Israel Deaconess Medical Center, Harvard Medical School, Boston, MA

\begin{abstract}
Objectives-To assess the prevalence of complementary and alternative medicine (CAM) use by U.S. adults reporting neuropsychiatric symptoms and whether this prevalence changes based on the number of symptoms reported. Additional objectives include identifying patterns of CAM use, reasons for use, and disclosure of use with conventional providers in U.S. adults with neuropsychiatric symptoms.
\end{abstract}

Design-Secondary database analysis of a prospective survey.

Participants-A total of 23,393 U.S. adults from the 2007 National Health Interview Survey.

Methods-We compared CAM use between adults with and without neuropsychiatric symptoms. Symptoms included self-reported anxiety, depression, insomnia, headaches, memory deficits, attention deficits, and excessive sleepiness. CAM use was defined as use of mind-body therapies (eg, meditation), biological therapies (eg, herbs), or manipulation therapies (eg, massage) or

() 2013 by the American Academy of Physical Medicine and Rehabilitation

Address correspondence to M.P.P.; mpurohit1@ partners.org.

M.P.P. Disclosure: support, institutional National Research Service Award \#T32AT000051 from the National Center for Complementary \&Alternative Medicine (NCCAM), NIH

R.E.W. Disclosure: support, institutional National Research Service Award \#T32AT000051 from the NCCAM, NIH; headache fellowship, American Headache Society

R.D.Z. Disclosure: support, Investigator Award \#5R24HD065688-02, NIDR, and the Department of Defense; royalties, demos, Brain Injury Medicare test; stipend, $P M \& R$ senior editor; principal investigator on a study funded by the U.S. Food and Drug Administration orphan drug program in collaboration with Neurohealing; nonfinancial, member of Neurohealing's scientific advisory board ACRM, J of Neurotrauma

R.B.D. Disclosure: Mid-Career Investigator Award \#K24AT000589

R.S.P. Disclosure: Mid-Career Investigator Award K24AT000589

The content is solely the responsibility of the authors and does not necessarily represent the official views of the NCCAM or the

National Institutes of Health. 
alternative medical systems (eg, Ayurveda). Statistical analysis included bivariable comparisons and multivariable logistical regression analyses.

Main Outcome Measures-The prevalence of CAM use among adults with neuropsychiatric symptoms within the previous 12 months and the comparison of CAM use between those with and without neuropsychiatric symptoms.

Results-Adults with neuropsychiatric symptoms had a greater prevalence of CAM use compared with adults who did not have neuropsychiatric symptoms (43.8\% versus $29.7 \%, P<$. 001 ); this prevalence increased with an increasing number of symptoms (trend, $P<.001$ ).

Differences in the likelihood of CAM use as determined by the number of symptoms persisted after we adjusted for covariates. Twenty percent of patients used CAM because standard treatments were either too expensive or ineffective, and 25\% used CAM because it was recommended by a conventional provider. Adults with at least one neuropsychiatric symptom were more likely to disclose the use of CAM to a conventional provider (47.9\% versus $39.0 \%, P$ $<.001)$.

Conclusion-More than $40 \%$ of adults with neuropsychiatric symptoms commonly observed in many diagnoses use CAM; an increasing number of symptoms was associated with an increased likelihood of CAM use.

\section{Introduction}

The National Institutes of Health defines complementary and alternative medicine (CAM) as "a group of diverse medical and health care systems, practices, and products that are not generally considered part of conventional medicine" [1]. Estimated out-of-pocket total expenditures for CAM in the United States in 2007 were $\$ 34$ billion, representing $1.5 \%$ of total health care costs and $11.2 \%$ of total out-of-pocket expenditures [2,3]. In comparison, consumers spent $\$ 49.6$ billion out of pocket for conventional physician visits and $\$ 52.5$ billion out of pocket for prescription medication in the same year [3]. The national prevalence of the use of at least one CAM modality in the general adult population was estimated to be more than $38 \%$ in 2007 [2].

What drives the use of CAM is less clear. It has been shown that patients with chronic medical conditions including low back pain or other chronic pain syndromes, bowel disease, and an irregular heartbeat report a greater likelihood of CAM use [4]. In addition, persons with neurologic disorders such as seizures and stroke also report a greater likelihood of CAM use [5]. Studies suggest that the use of CAM is greater when conventional treatments are unsatisfactory or ineffective [6,7]. Examples of diagnoses that fit this category include traumatic brain injury (TBI), fibromyalgia, and chronic pain syndromes [8-11].

Often underlying many of these difficult-to-treat diagnoses are difficult-to-treat neuropsychiatric symptoms. These symptoms may be associated with an increased prevalence of CAM use. In this context, we examined the use of CAM therapies among patients with neuropsychiatric symptoms by using a nationally representative database to determine whether persons with neuropsychiatric symptoms are associated with CAM use, the association between specific types of symptoms and the likelihood of CAM use, and the reasons for CAM use. We hypothesize that a much greater prevalence and likelihood of CAM use among adults with neuropsychiatric symptoms will be found compared with adults who do not have symptoms. 


\section{Methods}

\section{Data Source}

We analyzed data from the 2007 National Health Interview Survey (NHIS) Adult Core and Alternative Medicine Supplement. The NHIS is conducted by the Centers for Disease Control and Prevention and serves as the principal source of health information regarding the civilian, noninstitutionalized household population of the United States [12]. The NHIS uses a complex, multistage, stratified sampling design to select households for ComputerAssisted Personal Interviewing (face-to-face interviews), conducted in English and/or Spanish [12]. Minority populations (African Americans, Hispanics, and Asian Americans) are oversampled to provide more precise estimates for these populations [12]. One adult, age 18 years or older, was randomly selected from each household to answer the adult questionnaire [12]. In 2007, the NHIS used a supplement questionnaire, sponsored by the National Institutes of Health, to obtain information regarding national prevalence and reasons for CAM therapy use [12]. Details of the survey description, including specific questions and response options, are publicly available on the NHIS Web site $[12,13]$. Because of space limitations and to avoid duplication of information, we have not included those details here. The final adult survey included 23,393 respondents, with an overall response rate of $67.8 \%$ [12].

\section{Data Collection}

Neuropsychiatric Symptoms-According to the information surveyed, the most common neuropsychiatric symptoms include anxiety, insomnia, regular headaches, excessive sleepiness, attention deficits, memory loss, and depression [13].

Outcomes of Interest-Our primary outcome was the use of at least one CAM therapy in the previous 12 months, excluding prayer, vitamins, special diets, and traditional healers. We also were interested in the correlation between increasing number of neuropsychiatric symptoms and the prevalence of CAM use. Sampled adults were asked, "Have you used (specific therapy) in the past 12 months?" [12]. CAM therapies were grouped into 4 categories: alternative medical systems (eg, Ayurveda, acupuncture, homeopathy, and naturopathy), manipulation/bodywork therapies (eg, massage, chiropractic care, Feldenkrais, Alexander technique), biologically based therapies (eg, herbal therapies and chelation therapy), and mind-body therapies (eg, biofeedback, energy healing, hypnosis, tai chi, yoga, qi gong, meditation, guided imagery, progressive relaxation, and deep-breathing exercises).

In addition, we were interested in reasons for CAM use and disclosure of CAM use to conventional providers. Respondents were asked their reasons for CAM use and answered yes/no to each of 7 items: (1) to improve or enhance energy; (2) for general wellness/general disease prevention; (3) to improve/enhance immune function; (4) because conventional medical treatments did not help; (5) because conventional medical treatments were too expensive; (6) because it was recommended by a health care provider; or (7) because it was recommended by family, friends, or coworkers [12]. For each therapy used in the previous year, respondents were asked whether they disclosed their use to a conventional provider.

Correlates of CAM Use-Data also were collected on sociodemographic characteristics such as gender, age, race/ ethnicity, region of residence, birthplace, educational attainment, and marital status. Potential indicators of illness burden included perceived health status, presence of functional limitations, and self-reported history of medical conditions. Indicators of access to care included insurance status and imputed family income provided by the NHIS. Measures of health habits included smoking status, physical activity level, and alcohol intake. Other surveyed diagnoses included pain syndromes and rheumatic diseases 
such as fibromyalgia, arthritis, low back pain, and joint pain. Covariates were included either if they were previously reported as significant or if they were considered important and relevant to our topic $[4,5,14-16]$.

\section{Statistical Analyses}

We used bivariable analyses to compare the prevalence of CAM use, reasons for CAM use, and disclosure of CAM use to conventional providers between adults with and without neuropsychiatric symptoms. We also examined the correlation between an increasing number of neuropsychiatric symptoms and the prevalence of CAM use with $\chi^{2}$ analysis. To account for multiple comparisons in the descriptive data, we increased the threshold for significance to $P<.01$.

We fit multiple multivariable logistic regression models to determine (1) whether differences in CAM use persisted between adults with and without common neuropsychiatric symptoms after we adjusted for sociodemographic characteristics, illness burden, access to care, health habits, and other diagnoses; (2) whether an increase in the number of these symptoms was associated with an increase in CAM use after we adjusted for covariates; and (3) which specific symptoms were more closely associated with CAM use.

All models used the same covariates, including adjustments for sociodemographic characteristics, illness burden, access to care, health habits, and other diagnoses as previously described in detail. To ensure a robust analysis, we did not eliminate any of the covariates after initial inclusion.

The first model was a single multivariable model that analyzed whether having a neuropsychiatric symptom (independent of the number or type of symptoms) correlated with the likelihood of CAM use. The second model analyzed whether the number of neuropsychiatric symptoms was associated with a change in the likelihood of CAM use. The next set of models analyzed whether the specific type of neuropsychiatric symptom (eg, anxiety and insomnia) correlated with the likelihood of CAM use.

Prevalence estimates excluded missing data; no individual variable had more than 5.8\% missing data. Regression models included respondents with complete data on all covariates.

SAS (version 9.3; SAS Institute, Research Triangle Park, NC), a statistical software package, was used to account for the complex sample design via the use of NHIS parameters so that the results reflect national estimates [12]. Imputed incomes were provided by the NHIS. The study was approved for exemption by the Spaulding Rehabilitation Hospital Institutional Review Board because we used deidentified data.

\section{Results}

\section{Sample Characteristics}

Overall, 8696 adults reported experiencing at least one neuropsychiatric symptom, representing $36.6 \%$ of the U.S. adult population (an estimated 81.6 million adults nationwide). Overall, $18.1 \%$ (an estimated 40.4 million adults) reported insomnia, $15.2 \%$ (an estimated 33.9 million adults) reported regular headaches, $10.8 \%$ (an estimated 24.2 million adults) reported anxiety, $10.8 \%$ (an estimated 24.0 million adults) reported depression, $10.2 \%$ (an estimated 22.8 million adults) reported excessive sleepiness, $5.5 \%$ (an estimated 12.2 million adults) reported memory loss, and $2.9 \%$ (an estimated 6.4 million adults) reported attention deficit/hyperactivity disorder. Of the total population surveyed, 62.8\% (n $=14,697)$ of the population reported zero neuropsychiatric symptoms, $18.2 \%(\mathrm{n}=4261)$ 
reported 1 symptom, $8.5 \%(\mathrm{n}=1992)$ reported 2 symptoms, and $10.4 \%(\mathrm{n}=2443)$ reported 3 or more symptoms. Persons reporting one or more neuropsychiatric symptoms differed in many ways from persons without such symptoms (Table 1). Compared with persons without any symptoms, persons reporting one or more symptoms were more likely to be female and non-Hispanic white, to have less education and less income, to be less likely to have private insurance and more likely to need assistance with activities of daily living, to have a greater body mass index and perceive their health as fair or poor, to be a current smoker, and to have more comorbidities.

\section{Prevalence of CAM Use}

Overall, $43.8 \%$ of U.S. adults with at least one neuropsychiatric symptom reported using at least one CAM therapy in the previous 12 months, representing an estimated 36.6 million adults, compared with $29.7 \%$ of adults not reporting any neuropsychiatric symptoms $(P<$. $001)$. In unadjusted analyses, persons with neuropsychiatric symptoms differed significantly from persons without symptoms ( $P<.001$ for all covariates). The prevalence of CAM use increased with an increasing numbers of symptoms $(P<.001$; Figure 1$)$. Even after we adjusted for covariates, persons with at least one neuropsychiatric symptom were more likely to use CAM (odds ratio [OR] 1.55; 95\% confidence interval [CI] 1.44-1.66), and this likelihood increased with an increasing number of symptoms (OR for $\geq 3$ symptoms: 1.85 [95\% CI 1.64-2.09], Tables 2 and 3).

The following characteristics were all associated with a greater likelihood of CAM use: female gender; a greater level of education; a greater income; needing help with activities of daily living; perceiving one's health as good or better; having a greater level of physical activity; having a history of low back pain, head pain, or neck pain; and having a history of gastrointestinal disease, chronic lung disease, or rheumatic disease. Each individual neuropsychiatric symptom also was associated with an increased likelihood of CAM use (attention deficit, OR 1.72 [95\% CI 1.41-2.10]; anxiety, OR 1.67 [95\% CI 1.51-1.86]; insomnia, OR 1.46 [95\% CI 1.34-1.59]; excessive sleepiness, OR 1.41 [95\% CI 1.27-1.56]; depression, OR 1.35 [95\% CI 1.21-1.50]; memory loss, OR 1.29 [95\% CI 1.12-1.49]; and headaches, OR 1.13 [95\% CI 1.03-1.23]).

Adults with and without neuropsychiatric symptoms used mind-body therapies the most, followed by biologically based therapies, manipulation/body work therapies, and alternative medical systems (Figure 2). The most common mind—body therapies used among adults with and without neuropsychiatric symptoms were deep-breathing exercises (19.6\% and 9.6\%, respectively, $P<.001$ ), meditation (14.0\% and 7.4\%, $P<.001)$, and yoga (7.4\% and $5.7 \%, P<.001)$. Herbal therapies $(25.4 \%$ and $16.0 \%, P<.001)$ were the most common biologically based therapies used; chiropractic care $(13.7 \%$ and $8.3 \%, P<.001)$ and massage therapies $(12.3 \%$ and $7.3 \%, P<.001)$ were the most common manipulation therapies used; and homeopathy $(2.7 \%$ and $1.3 \%, P<.001)$ and acupuncture $(2.2 \%$ and $1.0 \%, P<.001)$ were the most common alternative medical systems used by adults with and without neuropsychiatric symptoms.

Adults with neuropsychiatric symptoms used CAM more often than those without symptoms because their provider recommended it (30.4\% versus 19.8\%), conventional treatment was not effective (18.3\% versus $10.6 \%$ ), and/or because conventional treatment was too expensive (9.7\% versus $3.7 \%$; Figure 3 ). Compared with persons with one or more neuropsychiatric symptom, persons without these symptoms had a greater prevalence of CAM use for general wellness or disease prevention $(69.7 \%$ versus $73.1 \%, P<.01$ for all analyses; Figure 3). Both groups used CAM therapies equally if a family or friend recommended it (44\% versus $42.1 \%$ ), for improving or enhancing energy (39\% versus $41.5 \%)$, and/or to improve or enhance immune function (29.0\% versus $26.8 \%$ ). 
More than half of all adults with neuropsychiatric symptoms did not report their CAM use to a conventional provider; persons with at least one neuropsychiatric symptom were more likely to disclose their use to a conventional provider compared with those without neuropsychiatric symptoms ( $47.9 \%$ versus $39.0 \%, P<.001)$.

\section{Discussion}

We found that U.S. adults with at least one neuropsychiatric symptom had a greater prevalence of CAM use compared with adults who did not have neuropsychiatric symptoms. More neuropsychiatric symptoms correlated with a greater prevalence of CAM use. Adults with and without neuropsychiatric symptoms used mind—body therapies the most and alternative medical systems the least. Respondents with attention deficit and anxiety had the greatest likelihood of CAM use. Persons with neuropsychiatric symptoms had a greater prevalence of CAM use if the therapy was recommended by a provider or if a conventional treatment was either ineffective or too expensive. Most users of CAM therapies did not discuss their use with a conventional provider.

The estimated prevalence of CAM use among the sample of adults with neuropsychiatric symptoms (43.8\%) is greater than published prevalence rates of CAM use in the general population (38.3\%) [2]. The estimated prevalence for this group was similar to the prevalence of CAM use among patients who survived a stroke (46\%) [17]. The closest approximation we could find to our study in terms of the patient population was a study evaluating CAM use among patients with an "anxiety attack" and severe depression; the prevalence for CAM use was $56.7 \%$ and $53.6 \%$, respectively [18]. However, that study included vitamin use and special diets in the definition of CAM, which we did not, because these treatments often are not considered alternatives to allopathic medicine. Unfortunately, we could not find a comparable study evaluating prevalence among patients with neuropsychiatric symptoms.

Regarding the efficacy of CAM use in patients with neuropsychiatric symptoms in various populations, preliminary data are promising, particularly for mind—body therapies. For example, in studies in which mindfulness-based stress reduction was used, authors demonstrated improvement for specific symptoms such as anxiety and insomnia [19-21]. In a pilot trial investigating mindfulness-based stress reduction for patients with TBI, the authors noted improvement in patients' quality of life and depression scores [22]. A pilot study in which acupuncture was used for patients with TBI revealed a preliminary benefit for cognition and perception of sleep quality [23].

Although investigators have shown promising evidence for neuropsychiatric symptoms in a few pilot studies, further research is needed to evaluate the efficacy of CAM in this condition. These studies, although well designed, had small sample sizes or limited control groups. It is important to be cautious because certain CAM therapies may have unintended consequences, especially when combined with conventional treatments, such as the use of certain herbal medications (eg, ginkgo biloba and St. John's wort) in combination with antiplatelet or serotonergic agents [24,25].

Our study has several limitations. Because the NHIS is conducted with U.S. adults, the results may not generalize to other populations. Like many surveys, the NHIS is crosssectional, relies on self-reporting, and is subject to recall bias and misclassification of information. However, the survey uses measures such as face-to-face interviews to minimize these issues.

Our study highlights the importance of screening for CAM use among patients with neuropsychiatric symptoms, such as patients with chronic pain syndromes, TBI, stroke, 
cancer, post-traumatic stress disorder, and rheumatic disorders, among many other possible diagnoses. This screening is especially important because most people who use CAM do not discuss this use with a conventional provider.

Understanding CAM use is important for several reasons. From a research perspective, if patients perceive certain treatments as beneficial, it is important to study those treatments to determine efficacy and safety. Even if a treatment may not heal the injury, it may provide other benefits such as improved quality of life that are important for overall care.

Furthermore, patient demand for treatments outside of standard care also may highlight the limits and dissatisfaction patients have with traditional care, which can provide an area of potential research and improvement. From a clinical perspective, knowledge of CAM use is important to be able to monitor for potential interactions with standard treatments and to provide patient counseling [24,26-28]. Given the high prevalence of the use of CAM, it is important for a provider to have an open and fair discussion with patients regarding safety and efficacy.

\section{Conclusion}

Our study shows a high prevalence of CAM use among patients with neuropsychiatric symptoms, with an increasing number of symptoms associated with increased use. Our results highlight the importance of clinicians discussing the role of CAM therapies with patients who have neuropsychiatric symptoms.

\section{Acknowledgments}

We acknowledge the review of earlier versions of this manuscript by Suzanne Bertisch, MD, MPH.

\section{References}

1. National Center for Compliementary and Alternative Medicine. [Accessed July 2, 2012] What is complementary and alternative medicine?. Available at http://nccam.nih.gov/health/whatiscam/ \#definingcam

2. Barnes PM, Bloom B, Nahin RL. Complementary and alternative medicine use among adults and children: United States, 2007. Natl Health Stat Rep. 2008 Dec.:1-23.

3. Centers for Medicare and Medicaid Services. [Accessed July 2, 2012] National Health Expenditures Aggregate, Per Capita Amounts, Percent Distribution, and Average Annual Percent Change: Selected Calendar Years 1960-2010. Available at https://www.cms.gov/NationalHealthExpendData/ downloads/tables.pdf

4. Bertisch SM, Wee CC, Phillips RS, McCarthy EP. Alternative mind-body therapies used by adults with medical conditions. J Psychosom Res. 2009; 66:511-519. [PubMed: 19446710]

5. Wells RE, Phillips RS, Schachter SC, McCarthy EP. Complementary and alternative medicine use among US adults with common neurological conditions. J Neurol. 2010; 257:1822-1831. [PubMed: 20535493]

6. Barnes PM, Powell-Griner E, McFann K, Nahin RL. Complementary and alternative medicine use among adults: United States, 2002. Adv Data. 2004 May 27.:1-19. [PubMed: 15188733]

7. Sirois FM, Gick ML. An investigation of the health beliefs and motivations of complementary medicine clients. Soc Sci Med. 2002; 55:1025-1037. [PubMed: 12220087]

8. Geoffroy PA, Amad A, Gangloff C, Thomas P. Fibromyalgia and psychiatry: 35 years later. . . What's new? Presse Med. 2012; 41:455-465. [in French]. [PubMed: 21993145]

9. Roth RS, Geisser ME, Theisen-Goodvich M, Dixon PJ. Cognitive complaints are associated with depression, fatigue, female sex, and pain catastrophizing in patients with chronic pain. Arch Phys Med Rehabil. 2005; 86:1147-1154. [PubMed: 15954053]

10. Rush BK, McNeil RB, Gamble DM, et al. Behavioral symptoms in long-term survivors of ischemic stroke. J Stroke Cerebrovasc Dis. 2010; 19:326-332. [PubMed: 20610187] 
11. Vaishnavi S, Rao V, Fann JR. Neuropsychiatric problems after traumatic brain injury: Unraveling the silent epidemic. Psychosomatics. 2009; 50:198-205. [PubMed: 19567758]

12. National Center for Health Statistics. [Accessed July 2, 2012] NHIS 2007 Survey Description Document 2008 June 2008. Available at ftp://ftp.cdc.gov/pub/Health_Statistics/NCHS/ Dataset_Documentation/NHIS/2007/srvydesc.pdf

13. Centers for Disease Control and Prevention. [Accessed July 2, 2012] National Health Interview Survey 2007. Available at http://www.cdc.gov/NCHS/nhis/nhis_2007_data_release.htm

14. Bertisch SM, Wee CC, McCarthy EP. Use of complementary and alternative therapies by overweight and obese adults. Obesity (Silver Spring, Md). 2008; 16:1610-1615.

15. Erwin Wells R, Phillips RS, McCarthy EP. Patterns of mind-body therapies in adults with common neurological conditions. Neuroepidemiology. 2011; 36:46-51. [PubMed: 21196772]

16. Carlson MJ, Krahn G. Use of complementary and alternative medicine practitioners by people with physical disabilities: Estimates from a National US Survey. Disabil Rehabil. 2006; 28:505-513. [PubMed: 16513583]

17. Shah SH, Engelhardt R, Ovbiagele B. Patterns of complementary and alternative medicine use among United States stroke survivors. J Neurol Sci. 2008; 271:180-185. [PubMed: 18485369]

18. Kessler RC, Soukup J, Davis RB, et al. The use of complementary and alternative therapies to treat anxiety and depression in the United States. Am J Psychiatry. 2001; 158:289-294. [PubMed: 11156813]

19. Gross CR, Kreitzer MJ, Reilly-Spong M, et al. Mindfulness-based stress reduction versus pharmacotherapy for chronic primary insomnia: A randomized controlled clinical trial. Explore (NY). 2011; 7:76-87. [PubMed: 21397868]

20. Joo HM, Lee SJ, Chung YG, Shin IY. Effects of mindfulness based stress reduction program on depression, anxiety and stress in patients with aneurysmal subarachnoid hemorrhage. J Kor Neurosurg Soc. 2010; 47:345-351.

21. Vollestad J, Sivertsen B, Nielsen GH. Mindfulness-based stress reduction for patients with anxiety disorders: Evaluation in a randomized controlled trial. Behav Res Ther. 2011; 49:281-288. [PubMed: 21320700]

22. Bedard M, Felteau M, Mazmanian D, et al. Pilot evaluation of a mind-fulness-based intervention to improve quality of life among individuals who sustained traumatic brain injuries. Disabil Rehabil. 2003; 25:722-731. [PubMed: 12791557]

23. Zollman FS, Larson EB, Wasek-Throm LK, Cyborski CM, Bode RK. Acupuncture for treatment of insomnia in patients with traumatic brain injury: A pilot intervention study. J Head Trauma Rehabil. 2012; 27:135-142. [PubMed: 21386714]

24. Gogtay NJ, Bhatt HA, Dalvi SS, Kshirsagar NA. The use and safety of non-allopathic Indian medicines. Drug Safety. 2002; 25:1005-1019. [PubMed: 12408732]

25. Graham, RE.; Gandhi, TK.; Borus, J., et al. Risk of concurrent use of prescription drugs with herbal and dietary supplements in ambulatory care. In: Henriksen, K.; Battles, JB.; Keyes, MA.; Grady, ML., editors. Advances in Patient Safety New Directions and Alternative Approaches, Vol. 4: Technology and Medication Safety. Rockville MD: Agency for Healthcare Research and Quality; 2008.

26. Kajiyama Y, Fujii K, Takeuchi H, Manabe Y. Ginkgo seed poisoning. Pediatrics. 2002; 109:325327. [PubMed: 11826216]

27. Poss J, Pierce R, Prieto V. Herbal remedies used by selected migrant farmworkers in El Paso, Texas. J Rural Health. 2005; 21:187-191. [PubMed: 15859058]

28. Raynor DK, Dickinson R, Knapp P, Long AF, Nicolson DJ. Buyer beware? Does the information provided with herbal products available over the counter enable safe use? BMC Med. 2011; 9:94. [PubMed: 21827684] 


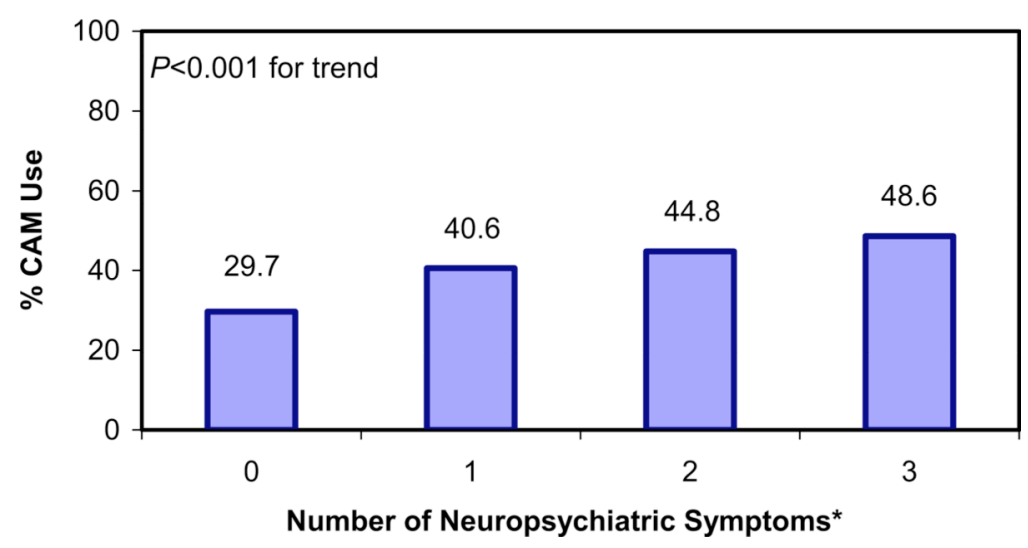

Figure 1.

Prevalence of CAM use by number of neuropsychiatric symptoms.

* Anxiety, depression, insomnia, headaches, memory deficits, attention deficits, and excessive sleepiness. 


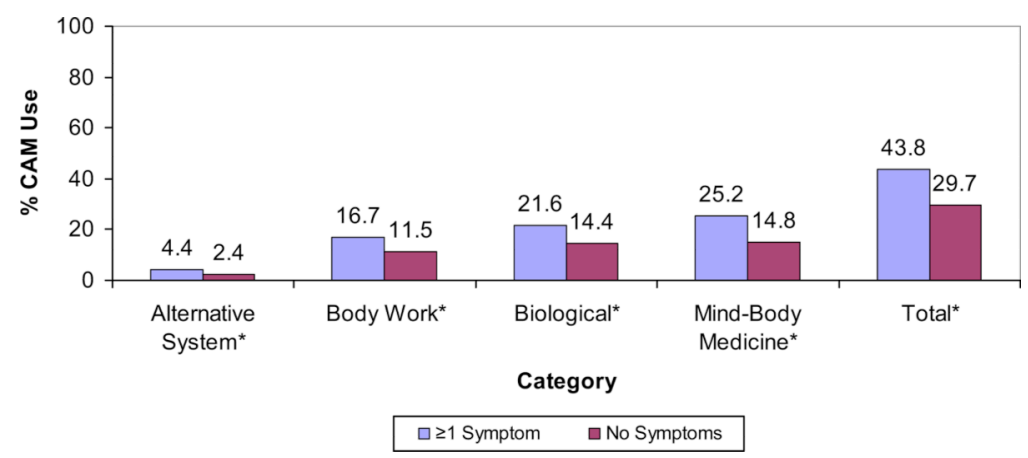

Figure 2.

CAM usage by modality; comparing patients with and without neuropsychiatric symptoms. $* P<.001$. 


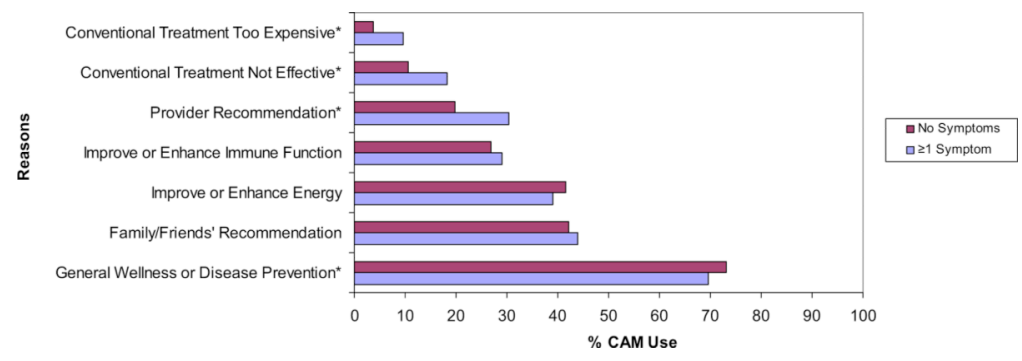

Figure 3.

Reasons for CAM use; comparing patients with and without neuropsychiatric symptoms.

$* P<.01$. 
Table 1

Sample characteristics of adults with and without neuropsychiatric symptoms known based on initial reviewer comments

\begin{tabular}{|c|c|c|}
\hline & $\begin{array}{l}\text { With Symptoms } \\
(\mathbf{n}=\mathbf{8 6 9 6}), \mathbf{n}(\%)\end{array}$ & $\begin{array}{l}\text { Without Symptoms } \\
(\mathrm{n}=14,692), \mathrm{n}(\%)\end{array}$ \\
\hline Total & $86960(307.2)$ & $14,692(62.8)$ \\
\hline \multicolumn{3}{|l|}{ Sociodemographic characteristics } \\
\hline \multicolumn{3}{|l|}{ Gender } \\
\hline Male & $3271(41.5)$ & $7102(52.2)$ \\
\hline Female & $5425(58.5)$ & $7590(47.8)$ \\
\hline \multicolumn{3}{|l|}{ Age, y } \\
\hline $18-24$ & $856(9.8)$ & $1638(13.3)$ \\
\hline $25-44$ & $2992(35.4)$ & $5548(37.7)$ \\
\hline $45-64$ & $2973(34.2)$ & $4801(34.1)$ \\
\hline $65-74$ & $900(8.8)$ & $1515(8.5)$ \\
\hline $75+$ & $975(9.5)$ & $1190(6.5)$ \\
\hline \multicolumn{3}{|l|}{ Race } \\
\hline Non-Hispanic white & $5322(71.1)$ & $8588(67.4)$ \\
\hline Non-Hispanic black & $1328(10.8)$ & $2296(11.8)$ \\
\hline Hispanic & $1477(12.2)$ & $2719(14.1)$ \\
\hline Asian & $346(3.4)$ & $862(5.1)$ \\
\hline Other & $223(2.5)$ & 227 (1.6) \\
\hline \multicolumn{3}{|l|}{ Education } \\
\hline$<$ High school & $1847(18.5)$ & $2376(14.0)$ \\
\hline High school & $2489(30.5)$ & $4031(28.0)$ \\
\hline >High school & $4296(51.0)$ & $8089(58.0)$ \\
\hline \multicolumn{3}{|l|}{ Imputed family income ${ }^{*}$} \\
\hline$\$ 0-19,999$ & $2716(22.9)$ & $2998(14.0)$ \\
\hline$\$ 20-34,999$ & $1839(20.3)$ & $2690(15.6)$ \\
\hline$\$ 35-64,999$ & $2094(26.2)$ & $4095(28.3)$ \\
\hline$>\$ 65,000$ & $2047(30.5)$ & $4909(42.1)$ \\
\hline \multicolumn{3}{|l|}{ Region } \\
\hline Northeast & $1389(15.9)$ & $2531(17.8)$ \\
\hline Midwest & $1918(23.6)$ & $3302(24.4)$ \\
\hline South & $3316(37.5)$ & $5399(36.2)$ \\
\hline West & $2073(23.0)$ & $3460(21.6)$ \\
\hline \multicolumn{3}{|l|}{ Marital status } \\
\hline Married/living with partner & $4059(58.5)$ & $7936(64.7)$ \\
\hline Widowed & $1020(8.1)$ & $1241(5.3)$ \\
\hline Divorced/separated & $1711(13.4)$ & $2075(9.3)$ \\
\hline Never married & $1881(20.0)$ & 3334 (20.7) \\
\hline U.S. born & $7251(86.6)$ & $11559(82.0)$ \\
\hline Foreign born & $1442(13.4)$ & $3118(18.0)$ \\
\hline
\end{tabular}




\begin{tabular}{|c|c|c|}
\hline & $\begin{array}{l}\text { With Symptoms } \\
(\mathbf{n}=\mathbf{8 6 9 6}), \mathrm{n}(\%)\end{array}$ & $\begin{array}{l}\text { Without Symptoms } \\
(\mathrm{n}=14,692), \mathrm{n}(\%)\end{array}$ \\
\hline \multicolumn{3}{|l|}{ Insurance status } \\
\hline Uninsured & $1572(17.9)$ & $2473(16.1)$ \\
\hline Medicare & $2269(22.7)$ & $2727(15.3)$ \\
\hline Medicaid & $784(7.8)$ & $681(3.6)$ \\
\hline Private & $3433(44.2)$ & $7741(57.7)$ \\
\hline Other & $617(7.5)$ & $1019(7.3)$ \\
\hline Needs help with ADLs $\dagger$ & $3386(37.6)$ & $2295(15.0)$ \\
\hline Does not need help with ADLs & $5310(62.4)$ & $12397(85.0)$ \\
\hline \multicolumn{3}{|l|}{ Health behavior characteristics } \\
\hline \multicolumn{3}{|l|}{ Body mass index } \\
\hline 18 to $<25$ & $2946(36.3)$ & $5505(39.9)$ \\
\hline 25 to $<30$ & $2645(32.0)$ & $5156(37.2)$ \\
\hline 30 to $<35$ & $1529(18.4)$ & $2132(15.6)$ \\
\hline$\geq 35$ & $1146(13.3)$ & $1057(7.4)$ \\
\hline \multicolumn{3}{|l|}{ Perceived health } \\
\hline Excellent/very good/good & $6370(75.0)$ & $13567(93.4)$ \\
\hline Fair or poor & $2321(25.0)$ & $1115(6.6)$ \\
\hline \multicolumn{3}{|l|}{ Physical activity } \\
\hline Low & $4120(45.8)$ & $5948(38.5)$ \\
\hline Moderate & $1354(16.0)$ & $2220(16.4)$ \\
\hline High & $3093(38.1)$ & $6232(45.1)$ \\
\hline \multicolumn{3}{|l|}{ Smoking } \\
\hline Current & $2114(26.0)$ & $2257(16.1)$ \\
\hline Former & $2062(23.8)$ & $2866(20.2)$ \\
\hline Never & $4397(50.1)$ & $9290(63.7)$ \\
\hline \multicolumn{3}{|l|}{ Consumption of alcohol } \\
\hline None & $3477(39.0)$ & 5755 (38.6) \\
\hline Light & $3526(43.1)$ & $5624(41.1)$ \\
\hline Moderate & $975(12.3)$ & $2014(15.5)$ \\
\hline Heavy & $461(5.6)$ & $645(4.9)$ \\
\hline \multicolumn{3}{|l|}{ Medical conditions or diagnoses } \\
\hline History of cardiovascular disease ${ }^{f}$ & $2100(22.2)$ & $1170(7.2)$ \\
\hline Without history of cardiovascular disease & $6595(77.8)$ & $13518(92.8)$ \\
\hline History of major neurologic disease $\xi$ & $811(9.2)$ & $312(1.9)$ \\
\hline Without history of major neurologic disease & $7883(90.8)$ & $14377(98.1)$ \\
\hline History of head or neck pain // & $3507(40.3)$ & $1922(13.2)$ \\
\hline Without history of head or neck pain & $5189(59.7)$ & $12765(86.8)$ \\
\hline Low back pain, past 3 mo & $3748(42.4)$ & $2318(15.9)$ \\
\hline Without low back pain, past 3 mo & $4939(57.6)$ & $12359(84.1)$ \\
\hline History of genitourinary disease ${ }^{* *}$ & $1266(13.6)$ & $595(3.9)$ \\
\hline Without history of genitourinary disease & $7428(86.4)$ & $14092(96.1)$ \\
\hline
\end{tabular}




\begin{tabular}{|c|c|c|}
\hline & $\begin{array}{l}\text { With Symptoms } \\
(\mathbf{n}=\mathbf{8 6 9 6}), \mathbf{n}(\%)\end{array}$ & $\begin{array}{l}\text { Without Symptoms } \\
(\mathrm{n}=14,692), \mathrm{n}(\%)\end{array}$ \\
\hline History of gastrointestinal disease ${ }^{\dagger \dagger}$ & $3499(40.0)$ & $2185(15.3)$ \\
\hline Without history of gastrointestinal disease & $5197(60.0)$ & $12504(84.7)$ \\
\hline History of chronic lung disease $\mathrm{t}^{t / t}$ & $1588(18.2)$ & $1216(8.4)$ \\
\hline Without history of chronic lung disease & $7106(81.8)$ & $13470(91.6)$ \\
\hline History of cancer & $907(10.1)$ & $877(5.8)$ \\
\hline Without history of cancer & 7779 (89.9) & $13804(94.2)$ \\
\hline Symptoms of joint pain/aching/stiffness in the past 30 days & $3851(43.8)$ & $2718(18.3)$ \\
\hline Without symptoms of joint pain/aching/stiffness in the past 30 days & $4835(56.2)$ & $11958(81.7)$ \\
\hline History of rheumatic disease ${ }^{\mathcal{B}} \mathcal{\xi}$ & $2868(31.8)$ & $2231(14.5)$ \\
\hline Without history of rheumatic disease & $5806(68.2)$ & $12439(85.5)$ \\
\hline
\end{tabular}

$\mathrm{ADL}=$ activities of daily living.

Percentages are weighted to reflect national estimates.

Incomes are imputed values provided by the National Health Interview Survey.

${ }^{\dagger}$ ADLs were defined as needing help with personal care, bathing/showering, dressing, eating, getting in/out of a chair/bed, toileting, getting around the home, routine needs, difficulty walking one-quarter of a mile without special equipment, difficulty climbing 10 steps without special equipment, difficulty standing for 2 hours without special equipment, difficulty sitting for 2 hours without special equipment, difficulty stooping/ bending without special equipment, difficulty reaching overhead, difficulty grasping small objects without special equipment, difficulty lifting/ carrying $10 \mathrm{lbs}$ or more without special equipment, difficulty pushing large objects without special equipment, or difficulty in going out or participate in social events without special equipment.

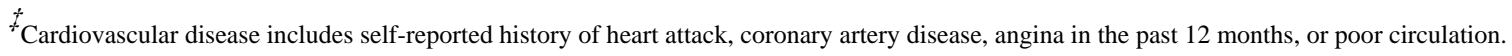

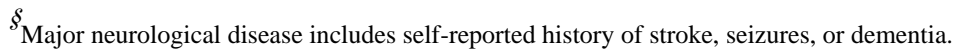

/ Head or neck pain includes self-reported history of dental pain in the past 12 months, jaw/face pain in the past 3 months, or neck pain in the past 3 months.

** Genitourinary disease includes self-reported history of urinary problems or weak/failing kidneys in the past 12 months.

${ }^{\dagger \dagger}$ Gastrointestinal disease includes self-reported history of acid reflux/heart burn, bowel problems, ulcer, or liver condition in the past 12 months.

${ }^{t}$ Chronic lung disease includes self-reported history of emphysema or asthma.

${ }^{\mathcal{S}}$ Rheumatic diseases included self-reported history of gout, lupus, fibromyalgia, rheumatoid arthritis, and/or arthritis. 
Table 2

Independent association of the presence of $\geq 1$ neuropsychiatric symptom with complementary and alternative medicine use: results from a single multivariable model

\begin{tabular}{|c|c|}
\hline Primary Factor & Odds Ratio (95\% CI) \\
\hline$\geq 1$ Neuropsychiatric symptom & $1.55(1.44-1.66)$ \\
\hline \multicolumn{2}{|l|}{ Adjustment factors } \\
\hline \multicolumn{2}{|l|}{ Gender } \\
\hline Male & $0.65(0.61-0.70)$ \\
\hline Female & 1.00 (reference) \\
\hline \multicolumn{2}{|l|}{ Age, y } \\
\hline $18-24$ & $0.87(0.77-0.98)$ \\
\hline $25-44$ & 1.00 (reference) \\
\hline $45-64$ & $0.99(0.92-1.08)$ \\
\hline $65-74$ & $1.07(0.88-1.30)$ \\
\hline $75+$ & $0.67(0.54-0.83)$ \\
\hline \multicolumn{2}{|l|}{ Race } \\
\hline Non-Hispanic white & 1.00 (reference) \\
\hline Non-Hispanic black & $0.55(0.43-0.69)$ \\
\hline Hispanic & $0.60(0.54-0.67)$ \\
\hline Asian & $1.11(0.94-1.30)$ \\
\hline Other & $1.13(0.91-1.40)$ \\
\hline \multicolumn{2}{|l|}{ Education } \\
\hline$<$ High school & $0.41(0.37-0.45)$ \\
\hline High school & $0.59(0.54-0.63)$ \\
\hline >High school & 1.00 (reference) \\
\hline \multicolumn{2}{|l|}{ Imputed family income } \\
\hline$\$ 0-19,999$ & $0.80(0.71-0.90)$ \\
\hline$\$ 20-34,999$ & $0.80(0.72-0.89)$ \\
\hline$\$ 35-64,999$ & $0.92(0.84-1.00)$ \\
\hline$>\$ 65,000$ & 1.00 (reference) \\
\hline \multicolumn{2}{|l|}{ Region } \\
\hline Northeast & $0.77(0.69-0.85)$ \\
\hline Midwest & $0.82(0.75-0.90)$ \\
\hline South & $0.70(0.64-0.76)$ \\
\hline West & 1.00 (reference) \\
\hline \multicolumn{2}{|l|}{ Marital status } \\
\hline Married/living with partner & 1.00 (reference) \\
\hline Widowed & $1.05(0.92-1.20)$ \\
\hline Divorced/separated & $1.14(1.04-1.25)$ \\
\hline Never married & $1.13(1.03-1.24)$ \\
\hline U.S. born & $1.10(0.98-1.22)$ \\
\hline Insurance status & \\
\hline
\end{tabular}




\begin{tabular}{|c|c|}
\hline Primary Factor & Odds Ratio (95\% CI) \\
\hline Uninsured & $0.98(0.88-1.08)$ \\
\hline Medicare & $0.92(0.77-1.10)$ \\
\hline Medicaid & $0.71(0.60-0.83)$ \\
\hline Private & 1.00 (reference) \\
\hline Other & $1.04(0.92-1.18)$ \\
\hline Needs help with ADLs & $1.23(1.13-1.33)$ \\
\hline \multicolumn{2}{|l|}{ Health behavior Body mass index } \\
\hline$<25$ & 1.00 (reference) \\
\hline 25 to $<30$ & $0.97(0.90-1.05)$ \\
\hline 30 to $<35$ & $0.98(0.89-1.07)$ \\
\hline 235 & $0.83(0.74-0.93)$ \\
\hline \multicolumn{2}{|l|}{ Perceived health } \\
\hline Excellent/very good/good & $1.22(1.09-1.36)$ \\
\hline Fair or poor & 1.00 (reference) \\
\hline \multicolumn{2}{|l|}{ Physical activity } \\
\hline Low & 1.00 (reference) \\
\hline Moderate & $1.77(1.61-1.94)$ \\
\hline High & $2.30(2.14-2.48)$ \\
\hline \multicolumn{2}{|l|}{ Smoking } \\
\hline Current & $0.92(0.84-1.00)$ \\
\hline Former & $1.31(1.21-1.42)$ \\
\hline Never & 1.00 (reference) \\
\hline \multicolumn{2}{|l|}{ Alcohol } \\
\hline None & 1.00 (reference) \\
\hline Light & $1.43(1.33-1.54)$ \\
\hline Moderate & $1.48(1.33-1.64)$ \\
\hline Heavy & $1.42(1.22-1.64)$ \\
\hline \multicolumn{2}{|l|}{ Medical conditions or diagnoses } \\
\hline History of major neurologic disease & $0.84(0.72-0.98)$ \\
\hline History of head or neck pain & $1.60(1.48-1.73)$ \\
\hline Low back pain, past 3 mo & $1.42(1.32-1.54)$ \\
\hline History of gastrointestinal disease & $1.24(1.15-1.34)$ \\
\hline History of chronic lung disease & $1.23(1.12-1.35)$ \\
\hline History of rheumatic disease & $1.36(1.15-1.60)$ \\
\hline
\end{tabular}

$\mathrm{ADL}=$ activities of daily living; $\mathrm{CI}=$ confidence interval.

Statistically significant results are presented. Of note, history of cardiovascular disease, genitourinary disease, cancer, and symptoms of joint pain/ aching/stiffness in the past 30 days were not statistically significant covariates. 
Table 3

Odds ratio of complementary and alternative medicine use based on the number of neuropsychiatric symptoms

\begin{tabular}{ll}
\hline No. of Symptoms as a Predictor & Odds Ratio (95\% CI) \\
\hline 23 symptoms & $1.85(1.64-2.09)$ \\
2 symptoms & $1.69(1.50-1.90)$ \\
1 symptom & $1.42(1.31-1.55)$ \\
No symptoms (reference) & 1.00 (reference) \\
\hline
\end{tabular}

$\mathrm{CI}=$ confidence interval.

Covariates for this model were the same as in Table 2. 